\title{
Bypass-Op. bei Diabetikern besser als Katheterdilatation
}

\section{Eine weitere Studie bestätigt, dass Diabetiker mit koronarer Mehrge- fäßerkrankung von einer Bypass- Operation mehr profitieren als von einer Revaskularisierung mittels Katheter (PCl).}

- In der VA CARDS-Studie erhielten 198 Diabetiker mit schwerer koronarer Mehrgefäßerkrankung oder einer isolierten proximalen Stenose der LAD nach Zufallskriterien entweder eine Bypass-Operation $(\mathrm{n}=97)$ oder Medikamenten-beschichtete Stents $(\mathrm{n}=101)$. Die Randomisierung wurde stratifiziert nach Zentrum, Insulinbehandlung (ja bzw. nein) und $\mathrm{HbA}_{1 \mathrm{c}}(\leq 8$ bzw. $>8 \%)$. Es konnten nur $25 \%$ der ursprünglich vorgesehenen Patienten rekrutiert werden.

Nach einer mittleren Beobachtungsdauer von zwei Jahren lag bei den operierten Patienten die Mortalität bei 5\% und die Herzinfarktrate bei $15 \%$, nach PCI bei 21 bzw. 6,2\% (jeweils signifikant). Diese gegenläufigen Ergebnisse führten aber bei dem primären Endpunkt aus Gesamtmortalität und In-

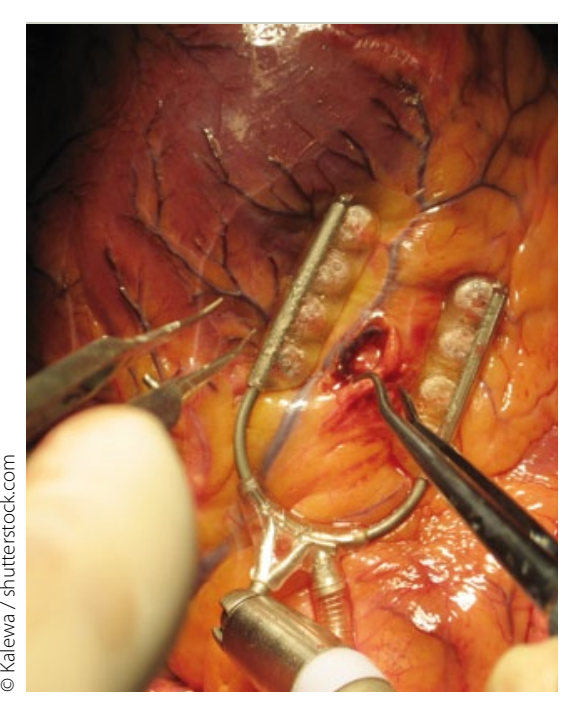

Bypass-Operation: Bei Diabetikern besser als der Stent.

farktrate zu einem signifikanten Vorteil für die Operation (18,4 vs. 25,3\%).

\footnotetext{
- M. Kamalesh et al.

Percutaneous Coronary Intervention Versus Coronary Bypass Surgery in United States Veterans With Diabetes. J. Am. Coll. Cardiol. 61 (2013) 808-816
}

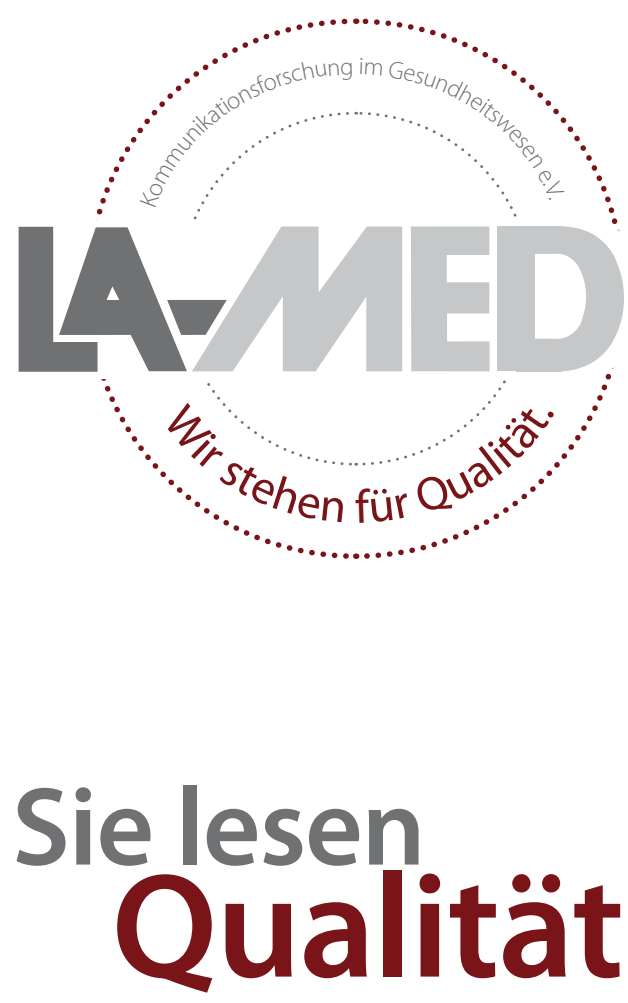

Damit das auch so bleibt, befragen wir Sie in Kooperation mit tns infratest in den nächsten Wochen.

Ihr Urteil ist uns wichtig. Bitte nehmen Sie teil! war aber bemängelt worden, dass einfache Stents eingesetzt wurden. Wenn jetzt in der VA CARDS-Studie die Bypass-Operation auch der Revaskularisierung mit Medikamentenbeschichteten Stents überlegen ist, rundet sie das Gesamtbild aus allen Daten ab. Aufgrund der gegenwärtigen Datenlage sollten, wie S. G. Ellis (Cleveland) in seinem Editorial schreibt, alle Diabetiker mit Mehrgefäßerkrankungen und komplexer Anatomie, evtl. sogar alle Diabetiker mit Mehrgefäßerkrankung, der Bypass-Operation zugeführt werden.

H. HOLZGREVE = einer Beobachtungsdauer von 3,8 Jahren der $\mathrm{PCl}$ zwar als deutlich überlegen erwiesen. Es 